\title{
Properties and Analysis of Transparency Conducting AZO Films by Using DC Power and RF Power Simultaneous Magnetron Sputtering
}

\author{
Neng-Fu Shih, ${ }^{1}$ Jin-Zhou Chen, ${ }^{2}$ and Yeu-Long Jiang ${ }^{3}$ \\ ${ }^{1}$ Department of Electronic Engineering, Hsiuping University of Science and Technology, Taichung 412-80, Taiwan \\ ${ }^{2}$ Graduate Institute of Optoelectronic Engineering, National Chung Hsing University, Taichung 402-27, Taiwan \\ ${ }^{3}$ Graduate Institute of Optoelectronic Engineering and Department of Electrical Engineering, National Chung Hsing University, \\ No. 250, Kuo Kuang Road, Taichung 402-27, Taiwan
}

Correspondence should be addressed to Neng-Fu Shih; nfshih@hust.edu.tw

Received 15 September 2013; Accepted 2 November 2013

Academic Editor: Shoou-Jinn Chang

Copyright (C) 2013 Neng-Fu Shih et al. This is an open access article distributed under the Creative Commons Attribution License, which permits unrestricted use, distribution, and reproduction in any medium, provided the original work is properly cited.

DC power and RF power were introduced into the magnetic controlled sputtering system simultaneously to deposit AZO films in order to get an acceptable deposition rate with high quality transparency conducting thin film. The resistivity decreases with the RF power for the as-deposited samples. The resistivity of $6 \times 10^{-4} \Omega$-cm and 3.5-4.5 $\times 10^{-4} \Omega$-cm is obtained for the as-deposited sample, and for all annealed samples, respectively. The transmittance of the AZO films with higher substrate temperature is generally above $80 \%$ for the incident light wavelength within $400-800 \mathrm{~nm}$. The transmittance of the as-deposited samples reveals a clear blue shift phenomenon. The AZO films present (002) oriented preference as can be seen from the X-ray diffraction curves. All AZO films reveal compressive stress. The annealing process improves the electrical property of AZO films. A significant blue shift phenomenon has been found, which may have a great application for electrode in solar cell.

\section{Introduction}

High transparent metal oxide semiconductor with band gap larger than the energy of visible light is usually a good insulator at room temperature [1]. Impurities doping is the easy way to increase conductivity. Tin doped indium oxide (ITO) [2], aluminum doped zinc oxide (AZO) [3, 4], and fluorine doped tin oxide $\mathrm{SnO}_{2}: \mathrm{F}$ (FTO) [5] are quite popular materials as transparent semiconductors. ITO, the best transparent conducting film, is a solid solution of indium (III) oxide $\left(\mathrm{In}_{2} \mathrm{O}_{3}\right)$ and tin (IV) oxide $\left(\mathrm{SnO}_{2}\right)$, typically $90 \%$ $\mathrm{In}_{2} \mathrm{O}_{3}, 10 \% \mathrm{SnO}_{2}$ by weight. However, with high cost and limited supplies of indium, alternatives are being sought. Another choice for transparency conducting film is FTO, which is widely used in dye-sensitized solar cell. However, it is very easy for hydrogen plasma to etch FTO, as well as tin oxide. The utilization of FTO and $\mathrm{SnO}_{2}$ in the thin film solar cell application is limited. AZO films are a good candidate as a transparent conductive material, because the materials (1) consist of cheap and abundant element, (2) are readily produced for large-scale coating, (3) allow tailing of ultraviolet absorption, (4) have a high stability in hydrogen plasma, and (5) have low growth temperature [6]. Besides, it is nontoxic and easy to fabricate. The reasons for higher conductivity of $\mathrm{Al}$ doped $\mathrm{ZnO}$ films can be attributed to extrinsic donor and intrinsic donor [7, 8]. The $\mathrm{Al}$ replaces $\mathrm{Zn}$ ions to form extrinsic donors, as well as from oxygen vacancies and $\mathrm{Zn}$ interstitial atoms to form intrinsic donor $[7,8]$. Production of the high conductivity and high transparency AZO films by controlling the intrinsic defects is highly desired for industrial application. Fang et al. deposited AZO film at $320^{\circ} \mathrm{C}$ by the DC sputtering with postdeposition annealing at $400^{\circ} \mathrm{C}$ for 2 hours under $10^{-3} \mathrm{~Pa}$ and got the resistivity as low as $1.5 \times 10^{-4} \Omega-\mathrm{cm}$ [6]. Park et al. used 
the RF sputtering method with $500^{\circ} \mathrm{C}$ high substrate temperature to get the lowest resistivity of $1.30 \times 10^{-4} \Omega-\mathrm{cm}$ [9]. Kim et al. used a DC cosputtering method followed by rapid thermal annealing to achieve a low resistivity of $1 \times 10^{-3} \Omega$-cm [10]. Ohta et al. investigated rapid thermal annealing of sputter-deposited $\mathrm{ZnO}$ and $\mathrm{AZO}$ films by using a radio-frequency ( $\mathrm{RF}$ ) argon thermal plasma jet at atmospheric pressure, and the lowest resistivity is around $3 \times 10^{-4} \Omega$-cm [11]. Exarhos et al. used 30\% $\mathrm{O}_{2} / \mathrm{Ar}$ gas mixture and $150 \mathrm{~W}$ RF sputtering method, followed by $4 \%$ hydrogen in argon $725 \mathrm{~K}$ annealing [12]. Chen et al. used $1.5 \%$ AZO target and $\mathrm{O}_{2} / \mathrm{Ar}$ gas mixture sputtering AZO film, followed by vacuum annealing, and analyzed its component with X-ray photoemission spectrum (XPS) and Auger electron spectrum (AES) [13]. Guillen et al. [14] used DC sputtering at room temperature, annealed it in vacuum at $350^{\circ} \mathrm{C}$, and got the best resistivity of $8 \times 10^{-4} \Omega$ $\mathrm{cm}$. Lee [15] uses RF sputtering in $\mathrm{H}_{2}$ and $\mathrm{Ar}$ mixture which reaches a minimum value of $4.4 \times 10^{-4} \Omega-\mathrm{cm}$ at the $\mathrm{H}_{2} /\left(\mathrm{H}_{2}+\mathrm{Ar}\right)$ gas ratio of $2.5 \%$. These AZO films are good choices for high conductivity and high transparency film. The AZO film made by RF sputtering seems to have better electrical property than that made by DC sputtering [16]. However, AZO film made by DC sputtering method has higher deposition rate than that made by RF sputtering method. Few factors will affect the quality, transparency, and conductivity of AZO films, such as grain size, crystallinity, and defects of different types [17]. In this work, we report the results of making AZO films using DC and RF sputtering simultaneous methods both as-deposited and annealed samples, to check their conductivity with acceptable deposition rate.

\section{Materials and Methods}

2.1. Specimen Preparation. Content of the target used in this work is 2 wt. $\% \mathrm{Al}_{2} \mathrm{O}_{3}$ and 98 wt. \% $\mathrm{ZnO}$. A corning 1737 glass was used as a substrate. After cleaning, the target and the substrate were put into a magnetron sputtering system and evacuated to $6.7 \times 10^{-3} \mathrm{~Pa}$. Then Ar gas with $70 \mathrm{~cm}^{3} / \mathrm{min}$ flow rate was introduced into the reaction chamber. After turning on the DC power supplier and RF power supplier, the target was presputtering for 5 minutes to remove surface contamination. Then open the shutter and sputter for $30 \mathrm{~min}$ at the pressures of $2.7 \times 10^{-1} \mathrm{~Pa}$. We have tested 3 different DC power suppliers to check the film quality with 30,50 , and $80 \mathrm{~W}$ and found that $80 \mathrm{~W}$ was the best choice for the film's quality. Therefore, the DC power supplier was kept at $80 \mathrm{~W}$, while the RF power was varied from $0 \mathrm{~W}$ to $120 \mathrm{~W}$. Five substrate temperatures $225,250,275,300$, and $325^{\circ} \mathrm{C}$ were chosen for deposition. After deposition, one group of substrates was put into a high temperature furnace under a $550^{\circ} \mathrm{C}$ substrate temperature with $6 \% \mathrm{H}_{2} / \mathrm{Ar}$ annealing for an hour to investigate the improvement of film quality. The thickness of films was measured by a Tencor alphastep 500 surface profiler, and the resistivity of films was measure by an ECOPIA model HMS-200 Hall Effect measurement system.
2.2. Crystalline Size. Crystalline size of AZO film can be evaluated from the FWHM of XRD peak and diffraction angle of the peak by the formula $[7,8]$

$$
D_{p}=\frac{0.94 \lambda}{\beta_{1 / 2} \cos \theta},
$$

where $D_{p}$ is the crystalline size, $\beta_{1 / 2}$ is the full width at half maximum of the diffraction peak, $\lambda$ is the incident X-ray wavelength $(=0.154 \mathrm{~nm})$, and $\theta$ is diffraction angle of the peak.

2.3. In-Plane Stress. For hexagonal crystals with a high $c$-axis preferred orientation, the in-plane stress can be calculated based on the biaxial strain model [18-20]:

$$
\sigma=\left[2 C_{13}-\frac{C_{33}\left(C_{11}+C_{12}\right)}{C_{13}}\right] \frac{\left(d-d_{0}\right)}{2 d_{0}},
$$

where $d$ is the interplaner spacing corresponding to (002) reflex in the XRD pattern, $d_{0}$ is that in bulk $\mathrm{ZnO}(0.2603 \mathrm{~nm})$, and $C_{i j}$ is elastic stiffness constants. The values of $d$ were calculated using Bragg formula $2 d+\sin \theta=n \lambda$.

2.4. Electrical Considerations. The doping of $\mathrm{Al}_{2} \mathrm{O}_{3}$ into $\mathrm{ZnO}$ structure is given by the equation $[6,10,21,22]$

$$
\mathrm{Al}_{2} \mathrm{O}_{3} \stackrel{\mathrm{ZnO}}{\longrightarrow} 2 \mathrm{Al}_{\mathrm{Zn}}{ }^{*}+2 \mathrm{O}_{\mathrm{o}}+\frac{1}{2} \mathrm{O}_{2}(g)+2 e,
$$

where $\mathrm{Al}_{\mathrm{Zn}}{ }^{*}$ is the substitutional $\mathrm{Al}, \mathrm{O}_{\mathrm{o}}$ is the oxygen vacancy, and $e$ is the free electron. For the AZO film annealing under a vacuum process, a considerable increase in conductivity was obtained due to the increase in oxygen defects, which acted as electron donors. In the meantime, the annealing process has the effect of increasing grain size and crystallinity of the film, which therefore results in less grain boundary scattering [9]. On the other hand, loss of oxygen from the crystal will also produce the interstitial zinc atoms according to the reaction $[6,10,21,22]$ :

$$
\mathrm{ZnO}-\mathrm{O}_{\mathrm{o}} \Longleftrightarrow \mathrm{Zn}_{i}{ }^{*}+e+\frac{1}{2} \mathrm{O}_{2}(g),
$$

where $\mathrm{Zn}_{i}{ }^{*}$ is the interstitial zinc atoms. It means that the intrinsic donor can be increased by the hydrogen annealing process, thus, increasing the conductivity.

\section{Results and Discussion}

3.1. Structural Characteristics and Film Stress. Figure 1 illustrates the X-ray diffraction (XRD) patterns for the AZO film. The XRD patterns were measured by the use of a Rigaku XRD model PC-2000. The full width at half maximum of the diffraction peak $\beta_{1 / 2}$ and diffraction angle of the peak $\theta$ are determined from XRD patterns as illustrated in Figure 1. The diffraction peak intensity increases with the increasing substrate temperature, as can be seen from Figure 1 . The increasing diffraction peak intensity of (002) between 225 and $325^{\circ} \mathrm{C}$ is primarily due to the crystallization of the AZO film. 


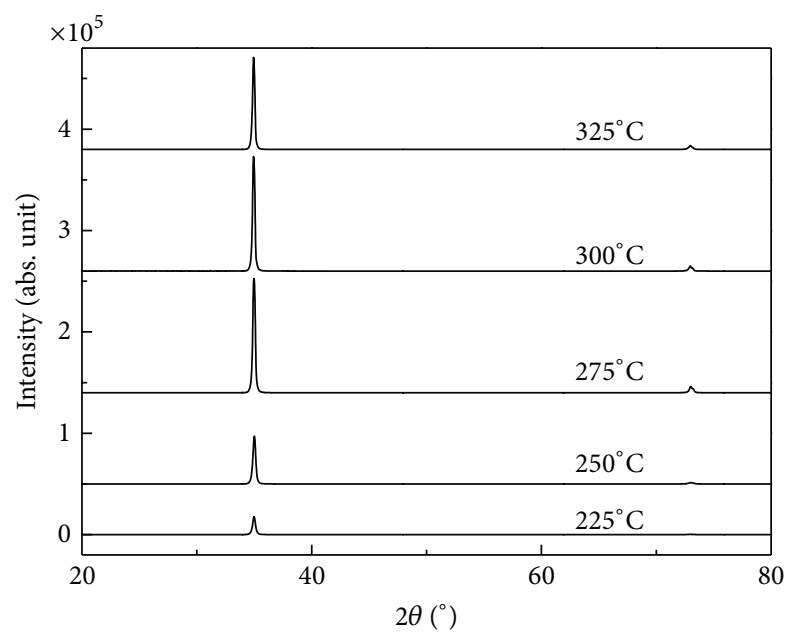

FIGURE 1: The XRD patterns for the AZO film deposited at a pressure of $2.7 \times 10^{-1} \mathrm{~Pa}$.

The solid squares in Figure 2(a) give the thickness for the sputtered AZO films versus incident RF power. The thicknesses of the sputtered films are around $963-1412 \mathrm{~nm}$. Obviously, the thickness increases with incident RF power for $\mathrm{RF}$ power $\leq 80 \mathrm{~W}$ but decreases with the incident RF power when RF power $>80 \mathrm{~W}$. The increase of the thickness for RF power $\leq 80 \mathrm{~W}$ is primarily due to the increasing total incident power. That increases the ionization rate of the introduced $\mathrm{Ar}$ gas. The decrease of the thickness with the incident RF power, when RF power $>80 \mathrm{~W}$, could be because positive cycle of the incident RF power is larger than the negative biased DC power $(=80 \mathrm{~W})$. That decreases the ionization rate of the introduced $\mathrm{Ar}$ gas. The deposition rates for $\mathrm{RF}$ power $=0$, $30,50,80,100$, and $120 \mathrm{~W}$ are $0.54,0.59,0.72,0.79,0.77$, and $0.75 \mathrm{~nm} / \mathrm{s}$, respectively. The crystalline sizes of AZO films are also given in Figure 2(a), where the open squares indicate asdeposited samples and open triangles annealing samples.

The crystalline sizes of AZO films are 37.5, 42.2, 44.0, 42.2, 44.0 , and $37.5 \mathrm{~nm}$ for RF power is $0,30,50,80,100$, and $120 \mathrm{~W}$, respectively. The crystalline sizes of the films generally are kept around $43 \mathrm{~nm}$, except when RF is $0 \mathrm{~W}$ or $120 \mathrm{~W}$. The crystalline sizes of AZO films are 37.5, 37.5, 39.0, 40.5, and $42.2 \mathrm{~nm}$ for the substrate temperature varies from 225,250 , 275,300 , to $325^{\circ} \mathrm{C}$, respectively. The crystalline sizes increase with the substrate temperature.

The solid squares in Figure 2(b) give the thickness versus substrate temperature. The deposition rate of AZO film is $0.60,0.68,0.68,0.66$, and $0.59 \mathrm{~nm}$ for substrate temperature of $225,250,275$, and 300 and $325^{\circ} \mathrm{C}$, respectively. The AZO film has the highest deposition at $250^{\circ} \mathrm{C}$ substrate temperature and then, decreases with the substrate temperature.

Figure 3(a) gives the in-plane stress for the AZO as deposited at $325^{\circ} \mathrm{C}$ with various RF power; the stress generally increases with the RF power. Figure 3(b) shows the in-plane stress for the AZO as deposited at 225, 250, 275, 300, and $325^{\circ} \mathrm{C}$, respectively. The results of Figure 3 are calculated from (2), where $C_{11}=208.8 \times 10^{9} \mathrm{~N} / \mathrm{m}^{2}, C_{33}=213.8 \times 10^{9} \mathrm{~N} / \mathrm{m}^{2}$, $C_{12}=119.7 \times 10^{9} \mathrm{~N} / \mathrm{m}^{2}$, and $C_{13}=104.2 \times 10^{9} \mathrm{~N} / \mathrm{m}^{2}$ were



(a)

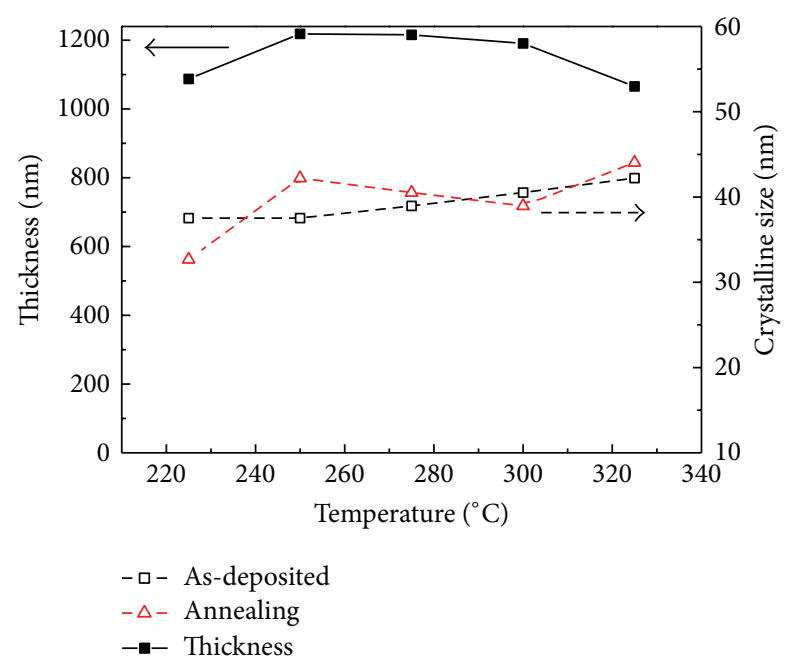

(b)

FIgURE 2: The thickness and the crystalline size for the sputtered AZO films versus (a) the incident RF power and (b) the substrate temperature.

used [17-19]. $80 \mathrm{~W}$ DC power and $30 \mathrm{~W}$ RF power were used during sputtering. The minus sign indicates the compressive stress. The stress generally increases with the RF power and increases to $1.41 \times 10^{9} \mathrm{~N} / \mathrm{m}^{2}$ from 225 to $250^{\circ} \mathrm{C}$ substrate temperature and then decreases to $0.40 \times 10^{9} \mathrm{~N} / \mathrm{m}^{2}$.

The total film stress contains thermal stress and intrinsic stress. The thermal stress comes from thermal mismatch between AZO thin films and glass substrate. The generation mechanism of the intrinsic stress was caused by the growth process itself. Since the thermal stress is very small, film stress is mainly caused by the growth process itself [18]. Comparing Figures 2 and 3, we conclude that higher deposition rate makes the film stress higher.

3.2. Electrical Characteristics. Figure 4 shows electrical property of the sputtered AZO film versus substrate temperature, 


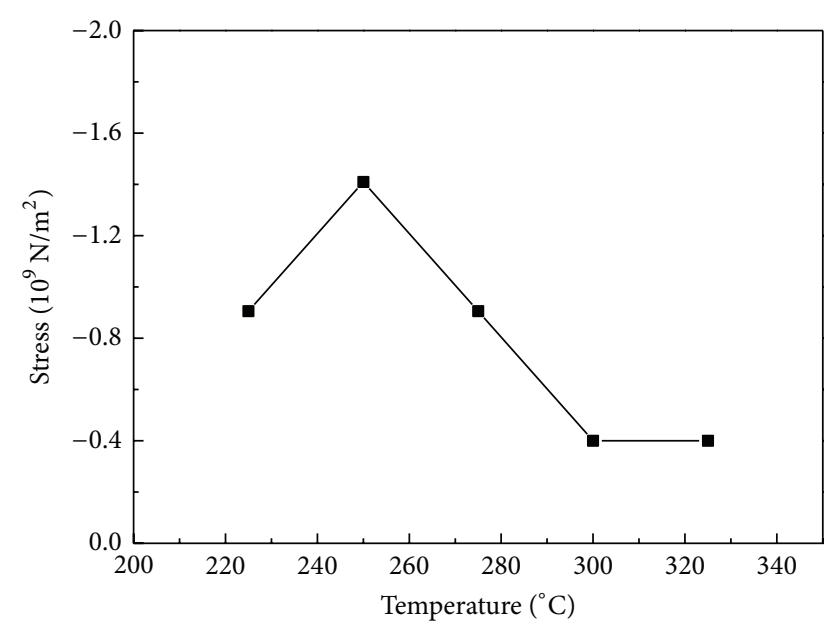

(a)

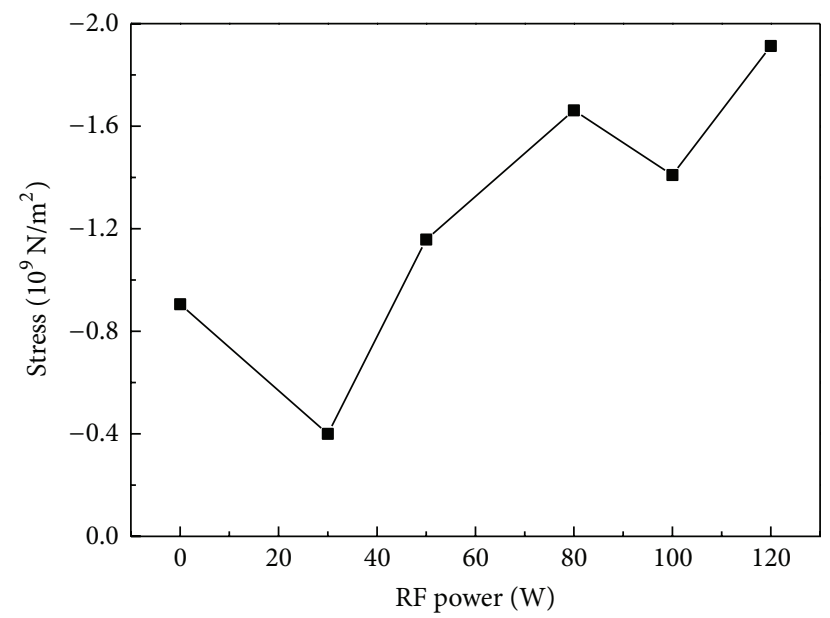

(b)

Figure 3: The in-plane stress for the $\mathrm{AZO}$ as deposited at $325^{\circ} \mathrm{C}$ with (a) various RF power and (b) various substrate temperatures.

where the dash lines indicate the resistivity, solid lines the electron concentration, and the dot lines the electron mobility, respectively. The squares indicate the as-deposited samples and the triangles the annealed samples, respectively.

The electron mobility for the annealed samples increases with the substrate temperature and is larger than that of the as-deposited samples, which could be due to the recrystallization of the annealed samples that increases the grain size which increase the electron mobility. The electron concentration of the annealed samples decreases with the increasing substrate temperature. For the as-deposited samples, both electron mobility and electron concentration increase with the increasing substrate temperature. Heating the AZO film, a considerable increase in conductivity was obtained due to the increase in oxygen defects, which increase the electron concentration in the film $[9,10]$. In the meantime, the thermal process has the effect of increasing grain size and crystallinity of the film, which results in less grain boundary scattering $[6,9,10]$. These combined actions increase the conductivity. Therefore, the resistivity decreases with the
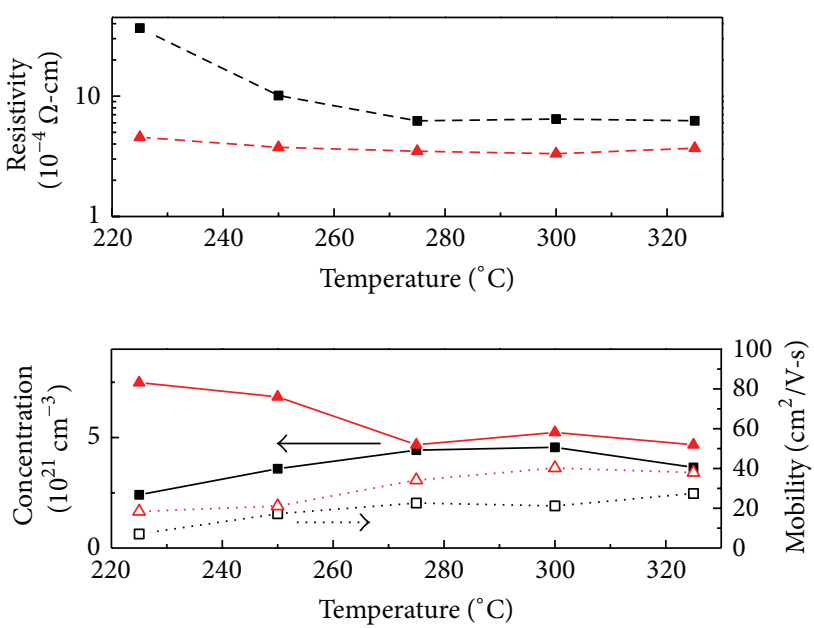

FIGURE 4: The electrical property of the sputtered AZO film versus the substrate temperature.

increasing substrate temperature except for the annealed samples, since the resistivity is reciprocal to the product of electron concentration and electron mobility. The resistivity of annealed samples, although decreasing with the increasing substrate temperature, was kept around 3.5-4.5 $\times 10^{-4} \Omega$-cm. This could be due to the decrease of electron concentration at higher substrate temperature. Hydrogen annealing process introduces the hydrogen into the AZO film, resulting in a shallow donor in AZO film [11].

Figure 5 shows electrical property of the sputtered AZO film versus RF power with substrate temperature $325^{\circ} \mathrm{C}$, where the dash lines indicate the resistivity, solid lines the electron concentration, and the dot lines the electron mobility, respectively. The squares indicate the as-deposited samples, and the triangles indicate the annealed samples, respectively. The resistivity of the as-deposited samples decreases with the RF power. The electron concentration increases slightly with the incident RF power for the as-deposited samples; however, the mobility of AZO film decreases slightly with the incident RF power.

3.3. Optical Properties. The transmittance was measured by the use of a Jasco model V-670 UV-VIS spectrophotometer. Figure 6 gives the transmittance of the as-deposited films for different substrate temperatures, where solid squares indicate $225^{\circ} \mathrm{C}$, open circles $250^{\circ} \mathrm{C}$, solid upper triangles $275^{\circ} \mathrm{C}$, open down triangles $300^{\circ} \mathrm{C}$, and solid diamonds $325^{\circ} \mathrm{C}$. The transmittance for the $\mathrm{AZO}$ film with $325^{\circ} \mathrm{C}$ substrate temperature is above $80 \%$ within the visible light region, and transmittance with 275 and $300^{\circ} \mathrm{C}$ substrate temperatures is around $80 \%$ for the incident wavelength around $400 \mathrm{~nm}$ and is above $80 \%$ for the incident wavelength longer than $450 \mathrm{~nm}$. The transmittance for substrate temperatures of 225 and $250^{\circ} \mathrm{C}$ is around $60 \%$ for the incident wavelength near $400 \mathrm{~nm}$ and is also above $80 \%$ for the incident wavelength longer than $450 \mathrm{~nm}$. This wider transmittance spectrum for high substrate temperature samples implicated the more absorption efficiency for the solar cell application. Particularly, 

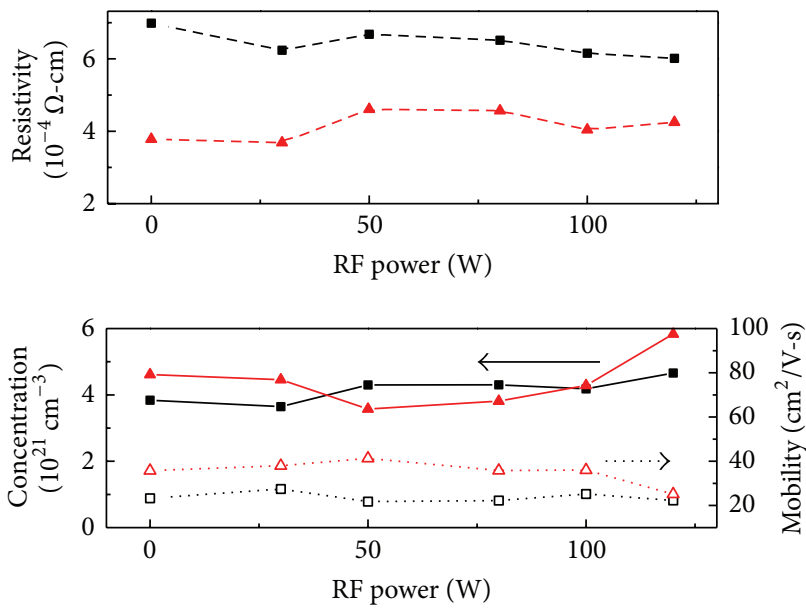

Figure 5: The electrical property of the sputtered AZO film versus the RF power.

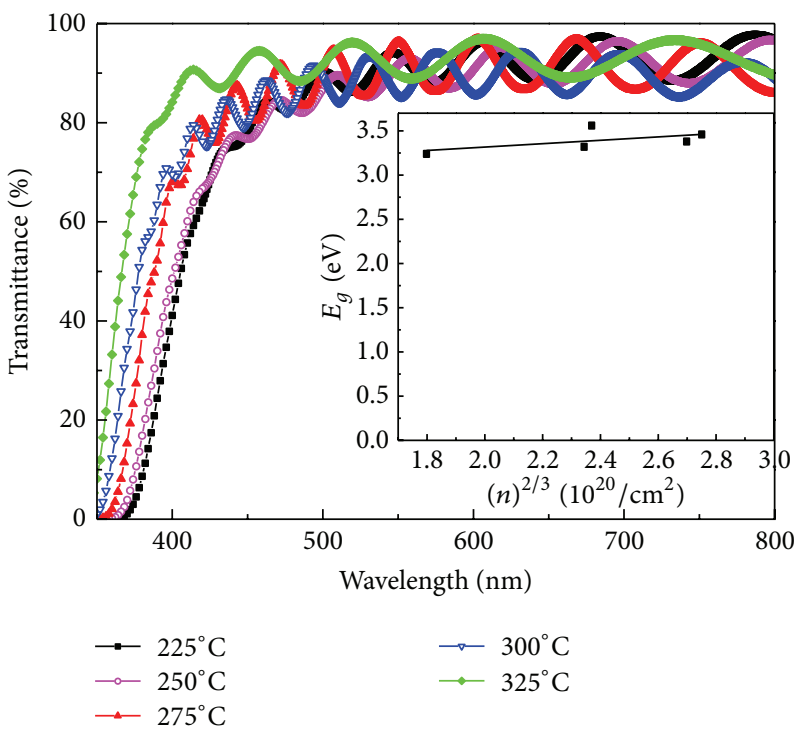

Figure 6: The transmittance of the as-deposited films for different substrate temperatures.

the transmittance of the as-deposited samples reveals a clear blue shift phenomenon. This is primarily due to the BursteinMoss shift effect $[12,23]$. Burstein-Moss shift is calculated by using the following equation:

$$
E_{F}-E_{\mathrm{CB}}=\left(\frac{\hbar^{2}}{2 m_{e}{ }^{*}}\right)\left(3 \pi^{2} n\right)^{2 / 3}
$$

where $m_{e}{ }^{*}$ is the electron effective mass, $E_{F}$ the Fermi level, $E_{\mathrm{CB}}$ the conduction-band edge, and $n$ the carrier concentration, respectively [12]. The insertion of Figure 5 gives optical band gap $E_{g}$ versus carrier concentration $n^{2 / 3}$ and reveals a good linear relationship between optical band gap $E_{g}$ and carrier concentration $n^{2 / 3}$. Therefore, we deduce that the blue shift of the transmission within $350-390 \mathrm{~nm}$ could be due to the Burstein-Moss shift effect.

\section{Summary and Conclusions}

AZO films were deposited by a magnetic control sputtering system using DC power and RF power simultaneously under different sputtering conditions. The AZO films present (002) oriented preference. The deposition rates for RF power $=0 \mathrm{~W}$ to $80 \mathrm{~W}$ increase from $0.54 \mathrm{~nm} / \mathrm{s}$ to $0.79 \mathrm{~nm} / \mathrm{s}$ which are good for mass production. In-plane stress for all AZO films reveals compressive stress. The stress increases with the RF power, increases to $1.41 \times 10^{9} \mathrm{~N} / \mathrm{m}^{2}$ from 225 to $250^{\circ} \mathrm{C}$ substrate temperature, and then decreases to $0.40 \times 10^{9} \mathrm{~N} / \mathrm{m}^{2}$. The transmittance for the film with higher substrate temperature is generally above $80 \%$ in the $400 \mathrm{~nm} \sim 800 \mathrm{~nm}$ visible light region. The electron mobility for the annealed samples is larger than that of the as-deposited samples due to the recrystallization of the annealed samples that increase the grain size, resulting in the increasing electron mobility. The lowest resistivity for the annealed samples is $3.5 \times 10^{-4} \Omega$ $\mathrm{cm}$ which is the best result ever reported by using DC and RF sputtering simultaneously. Furthermore, the sample with higher deposition temperature revealed a significant blue shift phenomenon which may have a great application for electrode in solar cell.

\section{Conflict of Interests}

The authors hereby declare that there is no conflict of interests with any financial organization regarding the material discussed in the paper.

\section{Acknowledgment}

This work was supported by the National Science Council Taiwan, under Grant NSC100-2221-E-164-004.

\section{References}

[1] J. L. Vossen, "Transparent conducting films," Physics of Thin Films, vol. 9, pp. 1-64, 1977.

[2] L. Davis, "Properties of transparent conducting oxides deposited at room temperature," Thin Solid Films, vol. 236, no. 1-2, pp. 1-5, 1993.

[3] H. W. Lehmann and R. Widmer, "Preparation and properties of reactively co-sputtered transparent conducting films," Thin Solid Films, vol. 27, no. 2, pp. 359-368, 1975.

[4] H. S. Randhawa, M. D. Matthews, and R. F. Bunshah, " $\mathrm{SnO}_{2}$ films prepared by activated reactive evaporation," Thin Solid Films, vol. 83, no. 2, pp. 267-271, 1981.

[5] E. Shanthi, A. Banerjee, V. Dutta, and K. L. Chopra, "Electrical and optical properties of tin oxide films doped with $\mathrm{F}$ and $(\mathrm{Sb}+\mathrm{F})$," Journal of Applied Physics, vol. 53, no. 3, pp. 1615-1621, 1982.

[6] G. Fang, D. Li, and B.-L. Yao, "Fabrication and vacuum annealing of transparent conductive AZO thin films prepared by DC magnetron sputtering," Vacuum, vol. 68, no. 4, pp. 363$372,2002$.

[7] B. D. Cullity and S. R. Stock, Elements of X-Ray Diffraction, Prentice-Hall, 3rd edition, 2001. 
[8] A. L. Patterson, "The scherrer formula for X-ray particle size determination," Physical Review, vol. 56, no. 10, pp. 978-982, 1939.

[9] J. H. Park, J. M. Shin, S.-Y. Cha et al., "Deposition-temperature effects on AZO thin films prepared by RF magnetron sputtering and their physical properties," Journal of the Korean Physical Society, vol. 49, no. 2, pp. S584-S588, 2006.

[10] Y. Kim, W. Lee, D.-R. Jung et al., "Optical and electronic properties of post-annealed ZnO:Al thin films," Applied Physics Letters, vol. 96, no. 17, Article ID 171902, 2010.

[11] N. Ohta, D. Ohba, S. Sato, Z. Tang, H. Shimizu, and H. Shirai, "Rapid thermal-plasma annealing of $\mathrm{ZnO}: \mathrm{Al}$ films for silicon thin-film solar cells," Thin Solid Films, vol. 519, no. 20, pp. 69206927, 2011.

[12] G. J. Exarhos, A. Rose, and C. F. Windisch Jr., "Spectroscopic characterization of processing-induced property changes in doped ZnO films," Thin Solid Films, vol. 308-309, no. 1-4, pp. 56-62, 1997.

[13] M. Chen, X. Wang, Y. H. Yu et al., "X-ray photoelectron spectroscopy and auger electron spectroscopy studies of Aldoped ZnO films," Applied Surface Science, vol. 158, no. 1, pp. 134-140, 2000.

[14] C. Guillén and J. Herrero, "Optical, electrical and structural characteristics of $\mathrm{Al}: \mathrm{ZnO}$ thin films with various thicknesses deposited by DC sputtering at room temperature and annealed in air or vacuum," Vacuum, vol. 84, no. 7, pp. 924-929, 2010.

[15] J.-H. Lee, "Effects of hydrogen incorporation and heat treatment on the properties of $\mathrm{ZnO}: \mathrm{Al}$ films deposited on polymer substrate for flexible solar cell applications," Current Applied Physics, vol. 10, no. 3, pp. S515-S519, 2010.

[16] W. Yang, Z. Wu, Z. Liu, A. Pang, Y.-L. Tu, and Z. C. Feng, "Room temperature deposition of Al-doped $\mathrm{ZnO}$ films on quartz substrates by radio-frequency magnetron sputtering and effects of thermal annealing," Thin Solid Films, vol. 519, no. 1, pp. 31-36, 2010.

[17] K. H. Ri, Y. B. Wang, W. L. Zhou, J. X. Gao, X. J. Wang, and J. Yu, "The effect of $\mathrm{SiO}_{2}$ buffer layer on the electrical and structural properties of $\mathrm{Al}$-doped $\mathrm{ZnO}$ films deposited on soda lime glasses," Applied Surface Science, vol. 257, no. 13, pp. 54715475, 2011.

[18] T. B. Bateman, "Elastic moduli of single-crystal zinc oxide," Journal of Applied Physics, vol. 33, no. 11, pp. 3309-3312, 1962.

[19] Y.-Y. Chen, P. W. Wang, J.-C. Hsu, and C.-Y. Lee, "Postannealing properties of aluminum-doped zinc oxide films fabricated by ion beam co-sputtering," Vacuum, vol. 87, pp. 227231, 2013.

[20] L. Li, L. Fang, X. M. Chen et al., "Influence of oxygen argon ratio on the structural, electrical, optical and thermoelectrical properties of Al-doped $\mathrm{ZnO}$ thin films," Physica E, vol. 41, no. 1, pp. 169-174, 2008.

[21] J. F. Chang, W. C. Lin, and M. H. Hon, "Effects of post-annealing on the structure and properties of Al-doped zinc oxide films," Applied Surface Science, vol. 183, no. 1-2, pp. 18-25, 2001.

[22] N. F. Shih, C. C. Lin, and C. Y. Kung, "Effect of oxygen contents on the properties of Al-Doped $\mathrm{ZnO}$ films prepared by low temperature magnetic controlled DC sputtering," Japanese Journal of Applied Physics, vol. 52, no. 1, Article ID 01AC07, 2013.

[23] B. E. Sernelius, K.-F. Berggren, Z.-C. Jin, I. Hamberg, and C. G. Granqvist, "Band-gap tailoring of $\mathrm{ZnO}$ by means of heavy Al doping," Physical Review B, vol. 37, no. 17, pp. 10244-10248, 1988. 

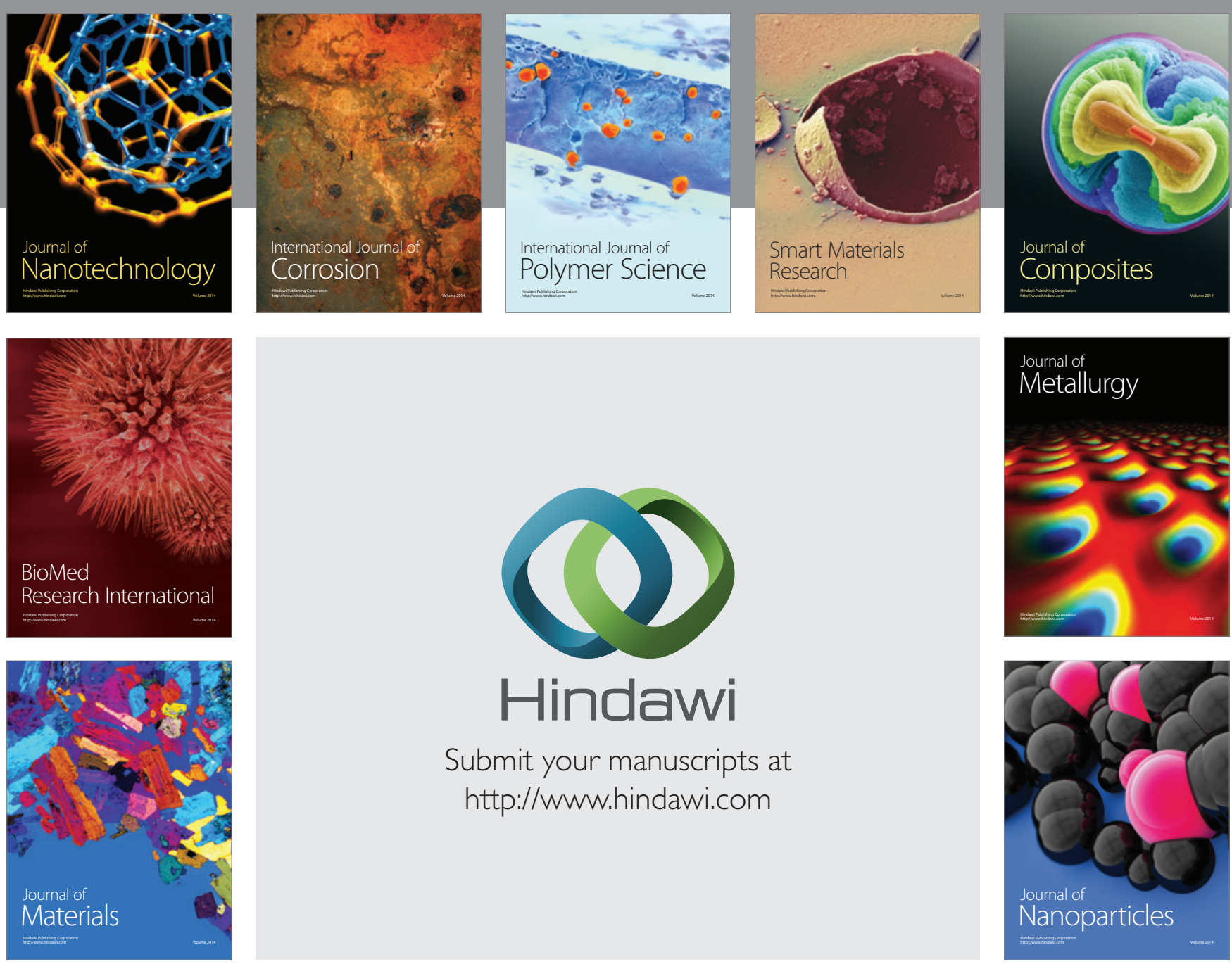

Submit your manuscripts at http://www.hindawi.com


\section{The Scientific World Journal}
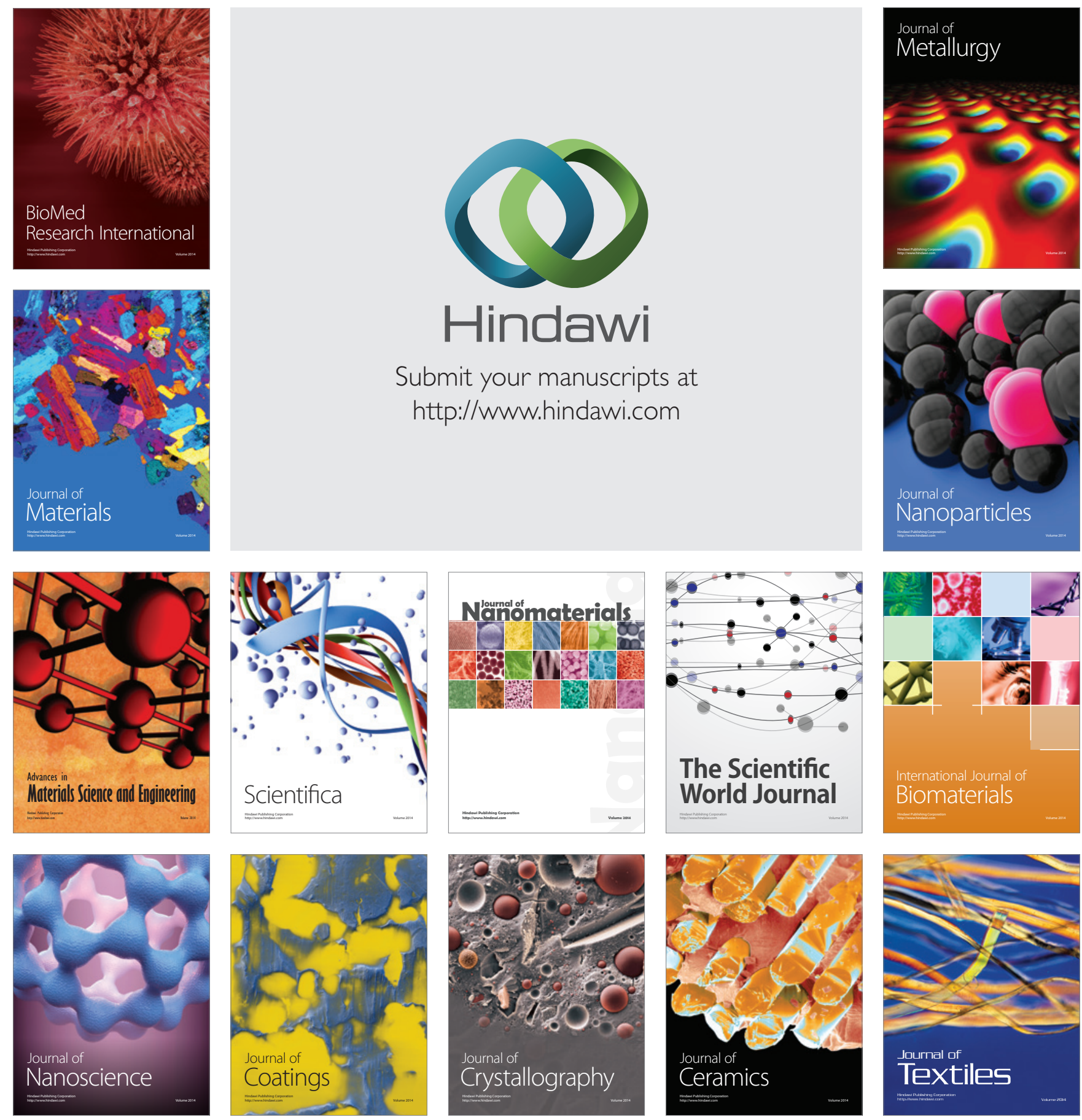